\title{
Lack of Influence of the ACE1 Gene I/D Polymorphism on the Formation and Growth of Benign Uterine Leiomyoma in Turkish Patients
}

\author{
Güldal Inal Gültekin ${ }^{1}$, Seda Güleç Yilmaz², Özlem Timirci Kahraman'1 Hande \\ Atasoy $^{2}$, A Burak Dalan ${ }^{3}$, Rukset Attar ${ }^{4}$, Ahmet Büyükören ${ }^{5}$, Nazlı Uçunoglu², \\ Turgay Isbir ${ }^{6 *}$
}

\begin{abstract}
Uterine leiomyomas (ULM), are benign tumors of the smooth muscle cells of the myometrium. They represent a common health problem and are estimated to be present in 30-70\% of clinically reproductive women. Abnormal angiogenesis and vascular-related growth factors have been suggested to be associated with ULM growth. The angiotensin-I converting enzyme (ACE) is related with several tumors. The aim of this study was to identify possible correlation between ULM and the $A C E \mathrm{I} / \mathrm{D}$ polymorphism, to evaluate whether the $A C E \mathrm{I} / \mathrm{D}$ polymorphism could be a marker for early diagnosis and prognosis. $A C E \mathrm{I} / \mathrm{D}$ was amplified with specific primer sets recognizing genomic DNA from ULM $(n=72)$ and control $(n=83)$ volunteers and amplicons were separated on agarose gels. The observed genotype frequencies were in agreement with Hardy-Weinberg equilibrium $\left(\chi^{2}=2.162, p=0.339\right)$. There was no association between allele frequencies and study groups $\left(\chi^{2}=0.623 ; p=0.430\right.$ for $A C E$ I allele, $\chi^{2}=0.995 ; \mathrm{p}=0.339$ for $A C E \mathrm{D}$ allele). In addition, there were no significant differences between $A C E \mathrm{I} / \mathrm{D}$ polymorphism genotype frequencies and ULM range in size and number $\left(\chi^{2}=1.760 ; p=0.415\right.$ for fibroid size, $\chi^{2}=0.342 ; p=0.843$ for fibroid number). We conclude that the $A C E$ gene I/D polymorphism is not related with the size or number of ULM fibroids in Turkish women. Thus it cannot be regarded as an early diagnostic parameter nor as a risk estimate for ULM predisposition.
\end{abstract}

Keywords: Angiogenesis - benign cancer - uterine fibroid - uterine myoma - ACE insertion/deletion

Asian Pac J Cancer Prev, 16 (3), 1123-1127

\section{Introduction}

Uterine leiomyomas (ULM), are benign tumors of the smooth muscle cells of the myometrium. They represent a common health problem and are estimated to be present in $30-70 \%$ of clinically reproductive women (Baird et al., 2003; Ekin et al., 2014; Tal and Segars, 2014). Although, ULM are rarely associated with mortality; they may significantly affect the quality of life with abnormal uterine bleeding, menorrahagia, infertility, complication of pregnancy and pelvic pain (Ekin et al., 2014). Ethnicity, nulliparity, obesity, diet, early age-at-menarche (Verit and Yucel, 2013) and age are reported among predisposing factors. Estrogen is proposed as the primary promoter of ULM (Flake et al., 2003). Furthermore, abnormal angionesis and vascular-related growth factors have been suggested to be associated with tumor growth (Tal and Segars, 2014). Up to date, a clear pathogenesis, including a genetic pathway has not been described for ULM (Catherino et al., 2013). However, several studies have shown that ULMs are influenced by genetics risk factors (Edwards et al., 2013), additionally; Hakverdi and colleagues (2013) recently discovered novel chromosome aberrations in ULM patients (Hakverdi et al., 2013).

The angiotensin-I converting enzyme (ACE) (EC:3.4.15.1) is located on chromosome 17q23.3, composed of 26 exons and 25 introns and expands over $20 \mathrm{~kb}$ (Gene ID: 1636). Three different isoforms have been described, differing in their $\mathrm{N}$-terminus regions, including the testicular (isoform 3) and the most abundant endothelial form (isoform 1). The isoform 1 produces nearly a $5000 \mathrm{bp}$ mRNA and a 1306 aa protein (NCBI, 2014). The ACE gene has been described with an insertion and deletion polymorphism (I/D) of a 287 bp Alu repeat within intron 16 (Rigat et al., 1990; Rigat et al., 1992). The polymorphism causes three possible genotypes, homozygous II and DD, and heterozygous ID. The homozygous DD is related to serum and tissue $A C E$ levels, and evidence suggests that the $\mathrm{D}$ allele is associated with elevated plasma and serum ACE levels compared to

${ }^{I}$ Department of Molecular Medicine, Institute of Experimental Medicine, ${ }^{5}$ Department of Gynecology, Faculty of Medicine, Istanbul University, ${ }^{2}$ Department of Molecular Medicine, Institute of Health Sciences, ${ }^{4}$ Department of Gynecology, ${ }^{3}$ Yeditepe University Hospital, ${ }^{6}$ Department of Medical Biology, Faculty of Medicine, Yeditepe University, Istanbul Turkey *For correspondence: turgay. isbir@yeditepe.edu.tr,tisbir@superonline.com 


\section{Güldal Inal Gültekin et al}

heterozygous ID and homozygous II alleles (Rigat et al., 1990). Several studies have been conducted to identify the relationship between the $A C E$ I/D polymorphism in cardiac, diabetes and panic disorder patients (Ergen et al., 2004; Isbir et al., 2007; Güleç et al., 2014). The variant has been widely investigated in cancer (van der Knaap et al., 2008; Zhang et al., 2014), including basal cell carcinoma (Yapijakis et al., 2013), lung (Cheng et al., 2014), breast (Fishchuk and Gorovenko, 2013; Li et al., 2014), oral (Vairaktaris et al., 2009), nasopharengeal (Li et al., 2012), hepatocellular (Yuan et al., 2013), gastric (Wei et al., 2014), colorectal cancer (Rocken et al., 2007; Liu et al., 2011), and polycystic ovary syndrome (Bayram et al, 2011; Jia et al., 2013).

The aim of this study is to identify a possible correlation between ULM formation risk, fibroid size and number and $A C E \mathrm{I} / \mathrm{D}$ polymorphism. Consequently to evaluate weather the $A C E$ I/D polymorphism could be suggested as a marker in the early diagnosis and possibly improve quality of life of affected women.

\section{Materials and Methods}

To conduct this study we used 2 groups, where healthy women $(n=83)$ and patients $(n=72)$ had pelvic imaging to detect the presence of ULM. The measurement of each fibroid was assessed with 3 perpendicular diameters: length, width and depth. Patients were grouped according to their fibroid number, being one or multiple; the latter including two up to 13 separate fibroids. A second grouping was made by tumor size, with the threshold selected at 5 $\mathrm{cm}$. The presence of pelvic pain and abnormal bleeding was noted, however not all women showed these signs. This study was approved by the Yeditepe University's Ethical Committee and informed, written consent was obtained from all volunteer participants.

\section{DNA isolation and genotyping for ACE I/ D polymorphism}

Peripheral blood $(10 \mathrm{ml})$ was collected into EDTA tubes in Departments of Gynaecology and Obstetrics, Istanbul and Yeditepe Universities, . Genomic DNA was extracted from peripheral whole blood using iPrep PureLink gDNA Blood Kit with the iPrep Purification Instrument (Invitrogen, Life Technologies, NY, USA). Consequently, DNA samples were quantified $(\mu \mathrm{g})$ and qualified (260/280 and 260/230) by the use of Nanodrop. The DNA samples were stored at $+4^{\circ} \mathrm{C}$ until genomic studies were conducted.

Polymerase chain reactions (PCR) were performed with 10 pmol for each primer: forward primer 5'-CTGGAGACCACTCCCATCCTTTCT-3', reverse primer 5'-GATGTGGCCATCTTCGTCAGAT-3' in final volume of $25 \mu \mathrm{l}$ containing $1.5 \mu \mathrm{l} \mathrm{MgCl} 2,0.5 \mathrm{mM}$ of each dNTP (PCR grade, Invitrogen, Life Technologies, NY, USA), and 0.25 unit Taq Polymerase (BIORON $\mathrm{GmbH}$, Germany). Amplifications were carried out in a DNA Thermal Cycler (Verite Thermal Cycler, Applied Biosystems) with an initial denaturation step at $94^{\circ} \mathrm{C}$ for 5 minutes, fallowed by 30 cycles of denaturation at $94^{\circ} \mathrm{C}$ for 1 minute, annealing at $58^{\circ} \mathrm{C}$ for 1 minute and extension at $72^{\circ} \mathrm{C}$ for 2 minutes, and a final extension at $72^{\circ} \mathrm{C}$ for 2 minutes as previously described (Rigat et al., 1992). PCR products were separated on $3 \%$ agarose gel and DNA was visualized by ethidium bromide staining. The amplification products at 190 and $490 \mathrm{bp}$ represent, the homozygous D and I alleles respectively. Those with both bands present represent the heterozygous ID alleles. Samples with DD genotype, were retyped with a second primer set, 5'-TGGGACCACAGCGCCCGCCACTAC-3' and 5'-TCGCCAGCCCTCCCATGCCCATAA-3', that specifically recognizes the insertion sequence, as described earlier (Ergen et al., 2004). Amplicons were obtained with a similar PCR cycle, with the annealing temperature set at $61^{\circ} \mathrm{C}$. A band present at 335 bp was considered to correspond to the I allele, thus those samples were interpreted as heterozygous ID alleles.

\section{Statistical analysis}

Frequency and statistical analysis were performed with SPSS 20.0. Data were presented as mean \pm standard deviation (SD) or as proportions. A $p<0.05$ was defined as statistically significant. Expected and observed frequencies of genotypes and alleles were compared with Chi-Square analysis and Fisher's exact tests. Nominal values were analyzed with Student-T test.

The sample size was calculated with the assumption that the prevalence of ULM is $20-30 \%$ of the population. To provide $80 \%$ power with a 0.05 alpha error, a minimum of 70 participants was found to be adequate, thus our study population $(n=72)$ was readily in the correct power.

\section{Results}

A total of 72 patients with ULM and 83 controls were recruited for this study. The mean age of patients and healthy controls were $36.64 \pm 9.63$ and $39.18 \pm 11.98$ years, respectively. No significant difference was found between patients and controls in terms of median age $(p=0.297)$.

Products amplified with the first and second primer sets were analysed using 3\% agarose gel electrophoresis (Figure 1 and 2). Products at 190 and 490 bp obtained with the first primer set, correspond to the homozygous D and I alleles respectively, those with both bands correspond to heterozygote genotype. Subjects with DD genotype were retyped with a second primer set, where a 325 bp product correspond to the I alleles and genotyped as heterozygote ID.

The genotype and allele frequencies of $A C E$ gene polymorphism among study and control groups are shown in Table 1. The observed genotype frequencies of $A C E$ gene polymorphism in study groups were in agreement with Hardy-Weinberg equilibrium $\left(\chi^{2}=2.162\right.$, $\mathrm{p}=0.339)$. Similarly, there was no association between allele frequencies and study groups $\left(\chi^{2}=0.623 ; \mathrm{p}=0.430\right.$ for $A C E$ I allele, $\chi^{2}=0.995 ; p=0.339$ for $A C E \mathrm{D}$ allele).

Distributions of $A C E$ II, ID and DD genotypes according to clinical parameters of ULM patients were examined. There were no significant difference between $A C E \mathrm{I} / \mathrm{D}$ polymorphism genotype frequencies and ULM range in size and number $\left(\chi^{2}=1.760 ; \mathrm{p}=0.415\right.$ for fibroid size, $\chi^{2}=0.342 ; p=0.843$ for fibroid number $)$. 


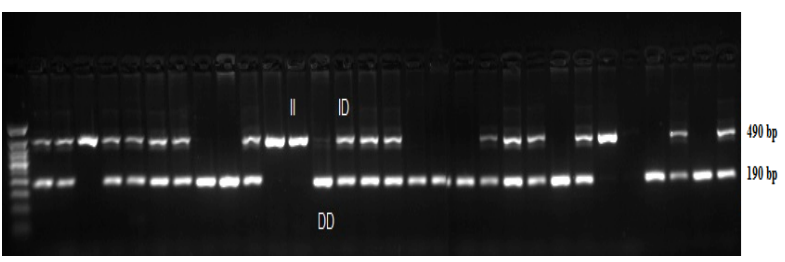

Figure 1. Individuals Homozygous for the D Allele (DD genotype) were Identified by the Presence of a Single 190 bp Product. Those homozygous for the I allele (II genotype) were identified by the presence of a single $490 \mathrm{bp}$ product. Heterozygous individuals (ID genotype) were identified by the presence of both $190 \mathrm{bp}$ and 490 bp products

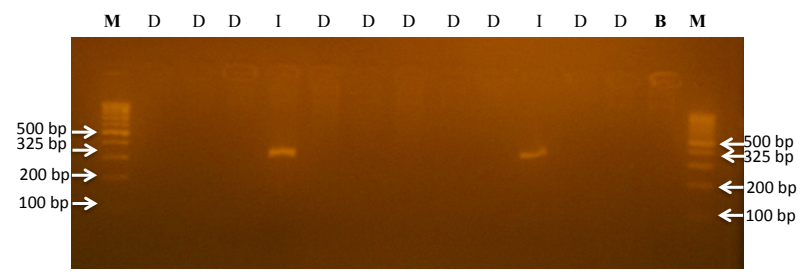

Figure 2. Visualization of DD Subjects with the Second

Primer Set. 100 bp marker (M) was used and the negative control (B-blank) was visualized in the last column of the $\% 3$ agarose gel. A band at $325 \mathrm{bp}$ was considered as the I allele and interpreted as heterozygote ID

Table 1. The Distribution of the ACE Genotypes and Allelic Frequency in the Study Groups

\begin{tabular}{lcccccc}
\hline ACE & $\begin{array}{c}\text { ULM } \\
(\mathrm{n})\end{array}$ & $\%$ & $\begin{array}{c}\text { Control } \\
(\mathrm{n})\end{array}$ & $\%$ & Total & $p$ value \\
\hline Genotype & & & & & & \\
$\quad$ II & 9 & 12.5 & 15 & 18.1 & 24 & \\
ID & 33 & 45.8 & 29 & 34.9 & 62 & 0.339 \\
DD & 30 & 41.7 & 39 & 47 & 69 & \\
Allele & & & & & & \\
I allele & 51 & 35.41 & 59 & 35.54 & 110 & 0.43 \\
D allele & 93 & 64.59 & 107 & 64.46 & 200 & 0.339 \\
\hline
\end{tabular}

Values are reported as number of patients (percentage of the total group); $\mathrm{n}$ : number of individuals; *p values less than 0.05 denoted statistical significance

\section{Discussion}

Here in we have compared the effects of the ACE I/ D polymorphism in ULM patients and healthy controls in a Turkish cohort. The benign ULMs represent the most common reason of hysterectomies in women and the estimated cost of ULM associated care has been reported as 34 billion dollars in the US only (Cardozo et al., 2012), representing a considerable burden on the healthcare system (Catherino et al., 2013). Although, a similar estimate was not reported for the European population, this number could potentially lower in the white race. However, it is well documented that the black race is more susceptible to develop ULMs compared to the white (Baird et al., 2003). It is reported that the disease is seen in $30-70 \%$ of reproductively active women and the risk diminishes post-menopause, thus exposure to estrogen significantly increases the risk of tumor formation (Baird et al., 2003; Catherino et al., 2013). Early age-at-menarche is also reported as one of the indications, as it provides a longer exposure to estrogen (Flake et al., 2003). Despite the implication of several etiologies for UML pathology, specific pathways and potential gene interactions are yet to be discovered. Heritability studies conducted in several European populations showed that 26-69\% of ULMs were due to genetic factors (Edwards et al., 2013).

The first genome-wide association study for ULM, was conducted in the Japanese population by Cha and colleagues, where they discovered 11 single nucleotide polymorphisms (SNPs) in 3 different chromosomal regions (Cha et al., 2011). Edwards and coworkers (2013) replicated the results from the Japanese study in the European American population and found a strong association between ULM risk and BET1L and TNRC6B genes (Edwards et al., 2013). Enzymes and their respective genes involved in the estrogen metabolic pathway, such as COMT, CYPIAl and CYP1B1 have been investigated in the Han Chinese population (Shen et al., 2014). It was concluded that COMT and CYPIAl had protective effects on the formation UMLs. Ateş and colleagues investigated the COMT Val158Met polymorphism and revealed its relevance to the formation of large fibroids. However, it was not attributed with the risk of ULM formation in a Turkish cohort (Ateş et al., 2013). Additionally, chromosomal structural aberrations have recently been reported in ULM patients, including, deletions, breaks and fragilities in several chromosomes (Hakverdi et al., 2013). Thus, it is well recognized by the scientific community, that the most common benign fibroid formation of the women reproductive tract depends on a genetic background.

The female reproductive organs, specifically the uterus undergoes cyclic physiological angiogenesis (Herr et al., 2013; Tal and Segars, 2014). Angiogenesis and sprouting of new blood vessels from existing ones is critical for the development of ULM (Risau, 1997; DiLieto et al., 2005; Tal and Segars, 2014). It has been previously stated that angionesis and vascular-related factors are involved in the formation and growth of ULM (DiLieto et al., 2005). Leiomyomas contain abnormal vascularization compared to the normal surrounding myometrium, such as that the vascular density of fibroids contains an avascular core, however they are enclosed in a dense vascular capsule (Tal and Segars, 2014).

The $A C E$ gene variations have been implicated in several chronic diseases, including coronary heart diseases (Alvarez et al., 2000), hypertension (Henskens et al., 2003), renal diabetes (Ergen et al., 2004) and recently in panic attack disorder (Gulec et al., 2014). The homozygous $\mathrm{DD}$ is related to serum and tissue $A C E$ levels, and evidence suggests that the $\mathrm{D}$ allele is associated with elevated plasma and serum $A C E$ levels (Rigat et al., 1990). The $A C E$ or kinase II enzyme is part renin-angiotensin system (RAS), which leads to hypertension by vasoconstriction as well as salt retention (Timmermans et al., 1993), thus regulating body fluid homeostasis. The RAS system has been characterized as a circulating hormonal system (Dinh et al., 2001). However, not many studies investigated the relevance of the RAS and the uterus (Herr et al., 2013).

In terms of cancer development, angiogenesis is essential for tumor progression and proliferation (Tal and Segars, 2014), and $A C E$ activity has been related with tumor growth (Fishchuk and Gorovenko, 2013). Such 


\section{Güldal Inal Gültekin et al}

as that $A C E$ inhibitors and angiotensin receptor blockers have been shown to suppress tumor growth (Mc Menamin et al., 2012).

In relation to cancer, $A C E 1$ gene I/D polymorphism has been widely investigated in Caucaisians and Asian populations. Meta-analysis reports conducted with the Chinese population reveals a lack of association between ACE1 I/D polymorphism and breast (Li et al., 2014), lung (Cheng et al., 2014), nasopharyngheal (Li et al., 2011) cancers and polycystic ovary syndrome (Jia et al., 2013). However an emphasis on racial differences is noticeable in some of the meta-analysis studies that further conducted subgroup analysis stratified by ethnicity (Li et al., 2011; Jia et al., 2013). A recent meta-analysis from Zhang et al. (2014), involving several cancer types, including breast, lung, colorectal, gastric and prostate cancers demonstrated that ACE1 I/D polymorphism was related to Caucasians but not to Asians (Zhang et al., 2014). In contrast, Wei et al. (2014) reported that the D allele was significantly associated with increased lymph node metastasis and advanced clinical stage for gastric cancer in the Chinese population (Wei et al., 2014). Furthermore, the D allele was related with increased risk of metastasis in colorectal cancer patients in Chinese subjects (Liu et al., 2011). Thus, discrepancies exist for different types of cancers. The Dutch population revealed increased risk for breast cancer development in subjects with the DD genotype (van der Knaap et al., 2008). The DD genotype was found to be associated with prolonged patient survival in favor for women with colorectal cancer in a German study (Rocken et al., 2007). The D allele was associated with an elevated risk in the formation of breast cancer in Ukrainian women (Fishchuk and Gorovenko, 2013). The I allele was found to be protective in women subjects with basal cell carcinoma compared to men (Yapijakis et al., 2013). One possible explanation for a mostly carcinogenic $\mathrm{D}$ allele might be due to its amplifier affects on $A C E$ gene expression, increasing angiotensin II production, which in turn leads to vasoconstriction, high blood pressure, cell proliferation and neovascularization (Fernandez et al., 1985; Yapijakis et al., 2013).

Beyond the formation of tumors, it is well known that angiotensin 2 receptor is highly abundant in the myometrium (Matsumoto et al., 1996; Dinh et al., 2001) and disappears during pregnancy (Matsumoto et al., 1996). Suggesting a possible role for $A C E$ during the physiological and pathological angiogenesis of the myometrium. The $A C E$ polymorphism was investigated in women with endometrial cancer, which is one of the most common gynecological malignancies in women of 50 to 70 years of age (Freitas Silva et al., 2004). Another study was conducted in Taiwanese women with endometriosis and ULM (Hsieh et al., 2007). In contradiction to most studies, both studies discovered that the presence of the I allele had a higher risk for developing endometrial cancer, endometriosis and leiomyoma (Freitas Silva et al., 2004; Hsieh et al., 2007).

Based on the evidence described above, here in we investigated the role of $A C E 1 \mathrm{I} / \mathrm{D}$ polymorphism on the most common pelvic benign tumor encountered in women worldwide. Contrary to must studies resulting with an unfavorable D allele; our study suggest that the $A C E$ polymorphism has no effect on the formation of uterine fibroids, in respect to their size $(\leq 5 \mathrm{~cm}<)$ and their number (one or multiple) in Turkish women. Additionally, the polymorphism had no effect on the risk of developing ULM in the Turkish cohort, and cannot be regarded as an early diagnostic parameter for ULM predisposition. This could be due to the benign nature of the ULM, however, the I allele was found detrimental in endometrial cancer in the Spanish population (Freitas Silva et al., 2004). Furthermore, most studies investigated the polymorphism with aggressive cancer types, such as gastric (Wei et al., 2014), breast (Fishchuk and Gorovenko, 2013), oral (Vairaktaris et al., 2009), and colorectal cancers (Röcken et al., 2007; Liu et al., 2011), as well as basal cell carcinoma (Yapijakis et al., 2013). This divergence could be due to the vascularization difference between benign ULM and other cancer types. Although our results indicate that the $A C E$ polymorphism is not related to ULM in Turkish women, racial effect might alter the result; hence, the discrepancy between our results and the Taiwanese study could be related to ethnical variations.

\section{References}

Alvarez R, Terrados N, Ortolano R, et al (2000). Genetic variation in the renin-angiotensin system and athletic performance. Eur J Appl Physiol, 82, 117-120.

Ates O, Demirturk F, Toprak M, et al (2013). Polymorphism of catechol-o-methyltransferase and uterine leiomyoma. $\mathrm{Mol}$ Cell Biochem, 375, 179-83.

Baird DD, Dunson DB, Hill MC, et al (2000). High cumulative incidence of uterine leiomyoma in black and white women: ultrasound evidence. Am J Obstet Gynecol, 188, 100-7.

Bayram B, Kilicci C, Onlu H, et al (2011). Association of angiotensin converting enzyme (ACE) gene I/D polymorphism and polycystic ovary syndrome (PCOS). Gene, 489, 86-8.

Cardozo ER, Clark AD, Banks NK, et al (2012). The estimated annual cost of uterine leiomyomata in the United States. Am J Obstet Gynecol, 206, 1-9.

Catherino WH, Eltoukhi HM, Al-Hendy A (2013). Racial and ethnic differences in the pathogenesis and clinical manifestations of uterine leiomyoma. Semin Reprod Med, 31, 370-9.

Cha PC, Takahashi A, Hosono N, et al (2011). A genome-wide association study identifies three loci associated with susceptibility to uterine fibroids. Nat Genet, 43, 447-50.

Cheng Z, Ma R, Tan W, et al (2014). Lack of association between $A C E$ insertion/deletion polymorphism and lung cancer: A meta-analysis. J Renin Angiotensin Aldosterone Syst, [Epub ahead of print].

Di Lieto A, De Falco M, Pollio F, et al (2005). Clinical response, vascular change, and angiogenesis in gonadotropin-releasing hormone analogue- treated women with uterine myomas. $J$ Soc Gynecol Investig, 12, 123-8.

Dinh DT, Frauman AG, Johnston CI, et al (2001). Angiotensin receptors: distribution, signaling and function. Clin Sci (Lond), 100, 481-92.

Edwards TL, Michels KA, Hartmann KE, et al (2013). BET1L and TNRC6B associate with uterine fibroid risk among European Americans. Hum Genet, 132, 943-53.

Ekin M. Cengiz H, Ozturk E, et al (2014). Genitourinary symptoms and their effects on quality of life in women with uterine myomas. Int Urogynecol J, 25, 807-10. 
ACE1 Gene I/D Polymorphism and Formation and Growth of Benign Uterine Leiomyoma in Turkish Patients

Ergen HA, Hatemi H, Agachan B, et al (2004). Angiotensin-I converting enzyme gene polymorphism in Turkish type 2 diabetic patients. Exp Mol Med, 36, 345-50.

Fernandez LA, Twickler J, Mead A (1985). Neovascularization produced by angiotensin II. J Lab Clin Med, 105, 141-5.

Fishchuk LE, Gorovenko NG (2013). Genetic polymorphisms of the renin-angiotensin system in breast cancer patients. Exp Oncol, 35, 101-4.

Flake GP,Andersen J, Dixon D (2003). Etiology and pathogenesis of uterine leiomyomas: a review. Environ Health Perspect, 111, 1037-54.

Freitas-Silva M, Pereira D, Coelho C, et al (2004). Angiotensin I-converting enzyme gene insertion/deletion polymorphism and endometrial human cancer in normotensive and hypertensive women. Cancer Genet Cytogenet, 155, 42-6.

Gülec-Yilmaz S, Yilmaz H, Dalan AB, et al (2014). The relationship between $A C E$ polymorphism and panic disorder. In Vivo, 28, 885-9.

Hakverdi S, Demirhan O, Tunc E, et al (2013). Chromosome imbalances and alterations in the p53 gene in uterine myomas from the same family members: familial leiomyomatosis in Turkey. Asian Pac J Cancer Prev, 14, 651-8.

Henskens LH, Spiering W, Stoffers HE, et al (2003). Effects of $A C E$ I/D and AT1R-A1166C polymorphisms on blood pressure in a healthy normotensive primary care population: first results of the hippocates study. J Hypertens, 21, 81-6.

Herr D, Bekes I, Wulff C (2013). Local renin-angiotensin system in the reproductive system. Front Endocrinol, 4, 1-7.

Hsieh YY, Lee CC, Chang CC, et al (2007). Angiotensin I-converting enzyme insertion-related genotypes and allele are associated with higher susceptibility of endometriosis and leiomyoma. Mol Reprod Dev, 74, 808-14.

Isbir SC, Tekeli A, Ergen A, et al (2007). Genetic polymorphisms contribute to acute kidney injury after coronary artery bypass grafting. Heart Surg Forum, 10, 439-44.

Jia H, Wang B, Yu L, et al (2013). Association of angiotensinconverting enzyme gene insertion/deletion polymorphism with polycystic ovary syndrome: a meta-analysis. J Renin Angiotensin Aldosterone Syst, 14, 255-62.

Li XL, Zheng ZJ, Qu HO (2014). Lack of association of angiotensin-converting enzyme insertion/deletion polymorphism with breast cancer: An update meta-analysis based on 10405 subjects. J Renin Angiotensin Aldosterone Syst, [Epub ahead of print].

Li ZH Pan XM, Han BW, et al (2012). No association between $A C E$ polymorphism and risk of nasopharyngeal carcinoma. $J$ Renin Angiotensin Aldosterone Syst, 13, 210-5.

Liu SY, Sima X, Wang CH, et al (2011). The association between $A C E$ polymorphism and risk of colorectal cancer in a Chinese population. Clin Biochem, 44, 1223-6.

Matsumoto T, Sagawa N, Mukoyama M, et al (1996). Type 2 angiotensin II receptor is expressed in human myometrium and uterine leiomyoma and is down-regulated during pregnancy. J Clin Endocrinol Metab, 81, 4366-72.

Mc Menamin UC, Murray LJ, Cantwell MM, et al (2012). Angiotensin-converting enzyme inhibitors and angiotensin receptor blockers in cancer progression and survival: a systematic review. Cancer Causes Control, 23, 221-30.

Rigat B, Hubert C, Alhenc-Gelas F, et al (1990). An insertion/ deletion polymorphism in the angiotensin I-converting enzyme gene accounting for half the variance of serum enzyme levels. J Clin Invest, 86, 1343-6.

Rigat B, Hubert C, Corvol P, et al (1992). PCR detection of the insertion/deletion polymorphism of the human angiotensin converting enzyme gene (DCP1) (dipeptidyl carboxypeptidase. Nucleic Acids Res, 20,1433.

Risau W (1997). Mechanisms of angiogenesis. Nature, 386,
671-4.

Rocken C, Neumann K, Carl-McGrath S, et al (2007). The gene polymorphism of the angiotensin I-converting enzyme correlates with tumor size and patient survival in colorectal cancer patients. Neoplasia, 9, 716-22.

Shen Y, Ren ML, Xu J, et al (2014). A multicenter case-control study on screening of single nucleotide polymorphisms in estrogen-metabolizing enzymes and susceptibility to uterine leiomyoma in han chinese. Gynecol Obstet Invest, 77, 224-30.

Tal R, Segars JH (2014). The role of angiogenic factors in fibroid pathogenesis: potential implications for future therapy. Hum Reprod Update, 20, 194-216.

The National Center for Biotechnology Information. http:// www.ncbi.nlm.nih.gov/gene/1636. Accessed January 2015.

Timmermans PB, Wong PC, Chiu AT, et al (1993). Angiotensin II receptors and angiotensin II receptor antagonists. Pharmacol Rev, 45, 205-51.

Vairaktaris E, Serefoglou Z, Avgoustidis D, et al (2009). Gene polymorphisms related to angiogenesis, inflammation and thrombosis that influence risk for oral cancer. Oral Oncol, 45, 247-53.

van der Knaap R, Siemes C, Coebergh JW, et al (2008). Reninangiotensin system inhibitors, angiotensin I-converting enzyme gene insertion/deletionpolymorphism, and cancer: the Rotterdam Study. Cancer, 112, 748-57.

Verit FF, Yucel O (2013). Endometriosis, leiomyoma and adenomyosis: the risk of gynecologic malignancy. Asian Pac J Cancer Prev, 14, 5589-97.

Wei MT, Chen N, He YZ, et al (2014). Angiotensin-converting enzyme insertion/deletion polymorphism and gastric cancer: A systematic review and meta-analysis. Clin Res Hepatol Gastroenterol, [Epub ahead of print].

Yapijakis C, Koronellos N, Spyridonidou S, et al (2013). Association of angiotensin-converting enzyme gene insertion/deletion polymorphism with decreased risk for basal cell carcinoma. Arch Dermatol Res, 305, 333-9.

Yuan F, Zhang LS, Li HY, et al (2013). Influence of angiotensin I-converting enzyme gene polymorphism on hepatocellular carcinoma risk in China. DNA Cell Biol, 32, 268-73.

Zhang K, Cheng D, Yi L, et al (2014). Association between angiotensin I-converting enzyme gene polymorphism and susceptibility to cancer: a meta analysis. Int J Clin Exp Pathol, 7, 6291-300. 